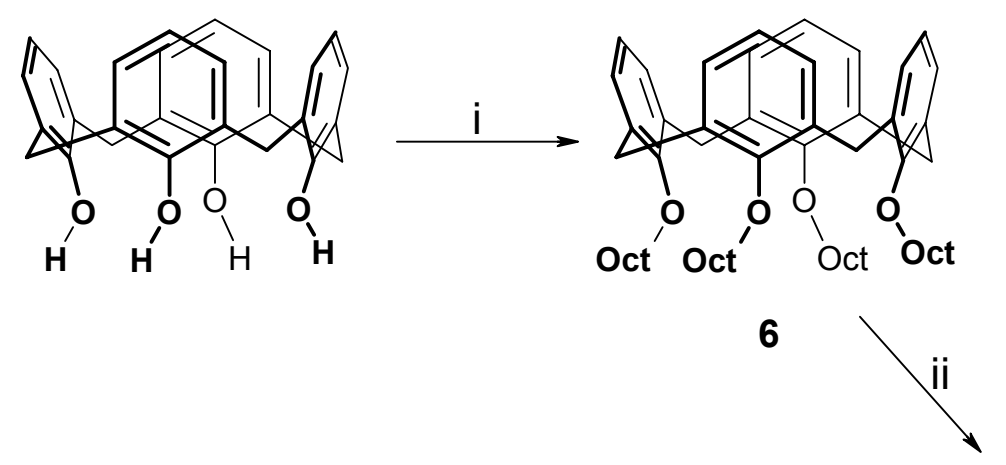

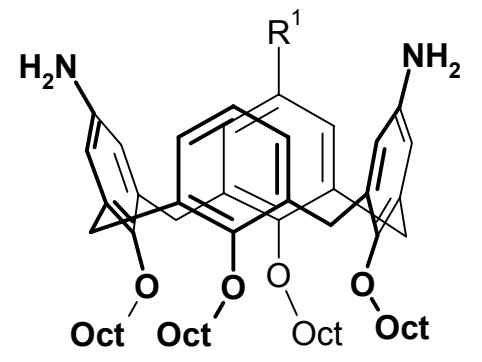

8a: $R^{1}=H$

8b: $R^{1}=\mathrm{NH}_{2}$

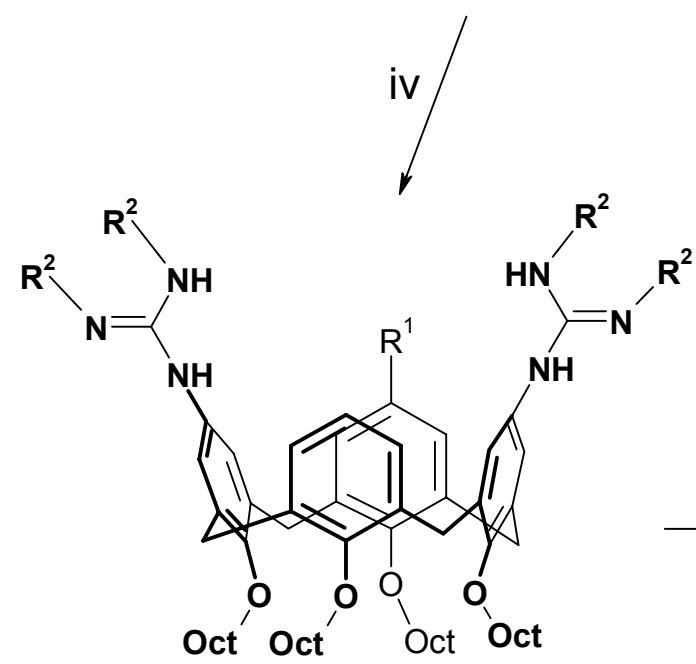

9a: $R^{2}=$ Boc, $R^{1}=H$

9b: $R^{2}=$ Boc, $R^{1}=-N$

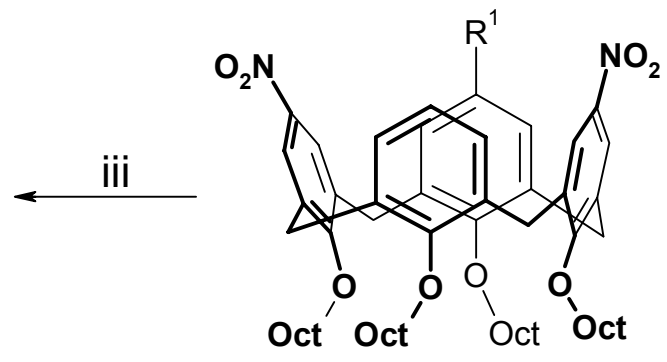

7a: $R^{1}=H$

7b: $\mathrm{R}^{1}=\mathrm{NO}_{2}$
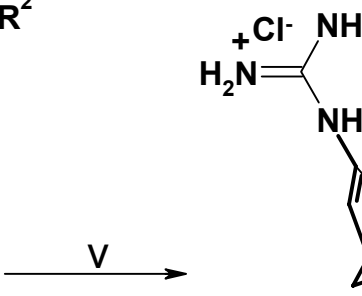

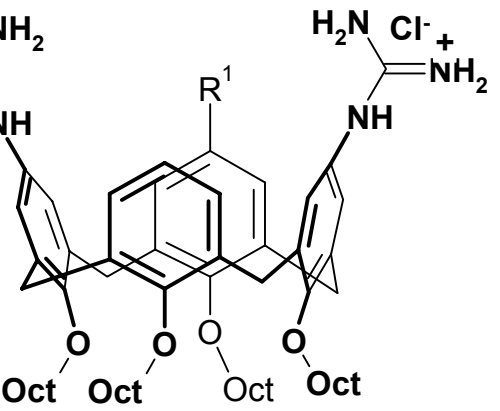

2G4Oct-cone: $\mathrm{R}^{1}=\mathrm{H}$ 3G4Oct-cone: $\mathrm{R}^{1}=-\underset{\mathrm{H}}{\mathrm{N}} \stackrel{+\underset{\mathrm{NH}_{2}}{\mathrm{Cl}^{-}-}}{\mathrm{NH}_{2}}$

(i) OctI, $\mathrm{NaH}$ in $\mathrm{DMF}$, r.t.; (ii) glacial acetic acid, $65 \% \mathrm{HNO}_{3}$ in $\mathrm{CH}_{2} \mathrm{Cl}_{2}$; (iii) $\mathrm{NH}_{2} \mathrm{NH}_{2} \cdot \mathrm{H} 2 \mathrm{O}, \mathrm{Pd} / \mathrm{C}(10 \%)$ in $\mathrm{EtOH}$, reflux; (iv) Boc-NH-C(S)-NH-Boc, Mukaiyama's reagent in $\mathrm{CH}_{2} \mathrm{Cl}_{2}$; (v) conc. $\mathrm{HCl} /$ 1,4-dioxane. 
25,26,27,28-Tetraoctyloxycalix[4]arene (6). To a solution of calix[4]arene (5.0 g, $\left.1.18 \times 10^{-2} \mathrm{~mol}\right)$ in dry DMF $(100 \mathrm{ml})$, cooled at $0{ }^{\circ} \mathrm{C}, \mathrm{NaH}(5.7 \mathrm{~g}, 0.14 \mathrm{~mol}, 55 \%$ in silicon oil) was added. The reaction mixture was stirred for $30 \mathrm{~min}$. and iodooctane $(17 \mathrm{ml}$, $\left.9.44 \times 10^{-2} \mathrm{~mol}\right)$ was added dropwise. The cooling bath was removed and the reaction was stirred at r.t. for $18 \mathrm{~h}$, then was quenched by addition of $\mathrm{HCl} 1 \mathrm{~N}(200 \mathrm{ml})$ and extracted with $\mathrm{CH}_{2} \mathrm{Cl}_{2}(2 \times 150 \mathrm{ml})$. The organic phase was washed with $\mathrm{HCl} 1 \mathrm{~N}(2 \times 150 \mathrm{ml})$, water $(2 \times 150 \mathrm{ml})$, dried over $\mathrm{MgSO}_{4}$ and evaporated under reduced pressure. The crude was purified by flash column chromatography on silica gel (eluent: hexane, hexane $/ \mathrm{CH}_{2} \mathrm{Cl}_{2} 4: 1$, $\mathrm{v}: \mathrm{v})$ and compound 6 was obtained as white solid in 75\% yield. M.p.: $60-62{ }^{\circ} \mathrm{C} .{ }^{1} \mathrm{H}$ NMR $\left(300 \mathrm{MHz}, \mathrm{CDCl}_{3}\right) \delta$ 6.70-6.60 (m, 12H, ArH), $4.50\left(\mathrm{~d}, J=13.2 \mathrm{~Hz}, 4 \mathrm{H}, \mathrm{ArCH} \mathrm{H}_{2} \mathrm{Ar}\right), 3.94(\mathrm{t}$, $\left.J=7.5 \mathrm{~Hz}, 8 \mathrm{H}, \mathrm{OCH}_{2}\left(\mathrm{CH}_{2}\right)_{6} \mathrm{CH}_{3}\right), 3.19\left(\mathrm{~d}, J=13.2 \mathrm{~Hz}, 4 \mathrm{H}, \mathrm{ArCH} \mathrm{Hr}_{2}\right), 2.08-1.90(\mathrm{~m}, 8 \mathrm{H}$, $\left.\mathrm{OCH}_{2} \mathrm{CH}_{2}\left(\mathrm{CH}_{2}\right)_{5} \mathrm{CH}_{3}\right), 1.39\left(\mathrm{bs}, 40 \mathrm{H}, \mathrm{O}\left(\mathrm{CH}_{2}\right)_{2}\left(\mathrm{CH}_{2}\right)_{5} \mathrm{CH}_{3}\right), 0.97$ (t, $J=7.2 \mathrm{~Hz}, 12 \mathrm{H}$, $\left.\mathrm{OCH}_{2}\left(\mathrm{CH}_{2}\right)_{6} \mathrm{CH}_{3}\right) .{ }^{13} \mathrm{C} \mathrm{NMR}\left(75 \mathrm{MHz}, \mathrm{CDCl}_{3}\right) \delta 156.6,135.1,128.1,121.8,75.1,32.0$, 31.0, 30.4, 30.0, 29.8, 26.4, 22.7, 14.1. MS (ESI): calculated for $[\mathrm{M}+\mathrm{Na}]^{+} \mathrm{m} / z=895.7$;

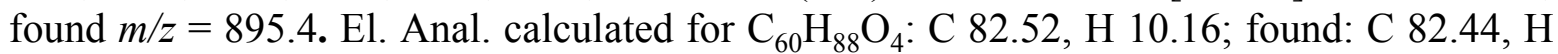
10.28 .

\section{5,17-Dinitro-25,26,27,28-tetraoctyloxycalix[4]arene (7a) and 5,11,17-trinitro-} 25,26,27,28-tetraoctyloxycalix[4]arene (7b). To a solution of 25,26,27,28tetraoctylcalix[4]arene $6\left(3 \mathrm{~g}, 3.34 \times 10^{-3} \mathrm{~mol}\right)$ in dry $\mathrm{CH}_{2} \mathrm{Cl}_{2}(60 \mathrm{ml})$, glacial acetic acid (48 $\mathrm{ml}, 0.84 \mathrm{~mol})$ and $65 \% \mathrm{HNO}_{3}(24 \mathrm{ml}, 0.34 \mathrm{~mol})$ were subsequently added. The mixture was stirred for $2 \mathrm{~h}$ and stopped by adding water $(200 \mathrm{ml})$. The mixture was extracted with $\mathrm{CH}_{2} \mathrm{Cl}_{2}(2 \times 100 \mathrm{ml})$ and the combined organic layers were dried over $\mathrm{MgSO}_{4}$. After flash column chromatography on silica gel (eluent: $\mathrm{CH}_{2} \mathrm{Cl}_{2}$ /hexane 2:1) $\mathbf{7 a}$ and $\mathbf{7 b}$ (yellow powders) were isolated in 32\% and 10\% yield, respectively. Compound 7a: M.p.: 135-137 ${ }^{\circ} \mathrm{C}\left(\mathrm{CH}_{2} \mathrm{Cl}_{2}-\mathrm{MeOH}\right) .{ }^{1} \mathrm{H}$ NMR $\left(300 \mathrm{MHz}, \mathrm{CDCl}_{3}\right) \delta 7.42(\mathrm{~s}, 4 \mathrm{H}, \mathrm{ArH}), 6.73(\mathrm{~m}, 6 \mathrm{H}, \mathrm{ArH})$, $4.46\left(\mathrm{~d}, J=13.6 \mathrm{~Hz}, 4 \mathrm{H}, \mathrm{ArCH}{ }_{2} \mathrm{Ar}\right), 3.92\left(\mathrm{~m}, 8 \mathrm{H}, \mathrm{OCH}_{2}\left(\mathrm{CH}_{2}\right)_{6} \mathrm{CH}_{3}\right), 3.25(\mathrm{~d}, J=13.7 \mathrm{~Hz}$, $\left.4 \mathrm{H}, \mathrm{ArCH} \mathrm{H}_{2} \mathrm{Ar}\right), 1.88\left(\mathrm{~m}, 8 \mathrm{H}, \mathrm{OCH}_{2} \mathrm{CH}_{2}\left(\mathrm{CH}_{2}\right)_{5} \mathrm{CH}_{3}\right), 1.31\left(\mathrm{~m}, 40 \mathrm{H}, \mathrm{O}\left(\mathrm{CH}_{2}\right)_{2}\left(\mathrm{CH}_{2}\right)_{5} \mathrm{CH}_{3}\right)$, $0.90\left(\mathrm{t}, J=6.3 \mathrm{~Hz}, 12 \mathrm{H}, \mathrm{O}\left(\mathrm{CH}_{2}\right)_{7} \mathrm{CH}_{3}\right) .{ }^{13} \mathrm{C} \mathrm{NMR}\left(75 \mathrm{MHz}, \mathrm{CDCl}_{3}\right) \delta 161.9,156.2,142.4$, 136.2, 134.1, 128.8, 123.3, 123.0, 75.7, 75.4, 31.9, 31.0, 30.3, 30.2, 29.8, 29.7, 29.5, 29.4, 26.2, 26.1, 22.6, 14.0. MS (ESI): calculated for $[\mathrm{M}+\mathrm{Na}]^{+} \mathrm{m} / z=985.7$; found $m / z=985.3$. El. Anal. calculated for $\mathrm{C}_{60} \mathrm{H}_{86} \mathrm{~N}_{2} \mathrm{O}_{8}: \mathrm{C} 74.81, \mathrm{H} \mathrm{9.00,} \mathrm{N} \mathrm{2.91;} \mathrm{found:} \mathrm{C} \mathrm{74.65,} \mathrm{H} \mathrm{8.98,} \mathrm{N}$ 3.08. Compound 7b: ${ }^{1} \mathrm{H}$ NMR $\left(300 \mathrm{MHz}, \mathrm{CDCl}_{3}\right) \delta 7.80$ (s, 2H, $\left.\mathrm{ArH}\right), 7.79(\mathrm{~s}, 2 \mathrm{H}, \mathrm{ArH})$, 7.24 (s, 2H, ArH), 6.36 (s, 3H, ArH), 4.50 (d, $\left.J=14.2 \mathrm{~Hz}, 2 \mathrm{H}, \operatorname{ArCH}_{2} \mathrm{Ar}\right), 4.45$ (d, $J=14.2$ $\left.\mathrm{Hz}, 2 \mathrm{H}, \mathrm{ArCH}_{2} \mathrm{Ar}\right), 4.15-3.97\left(\mathrm{~m}, 4 \mathrm{H}, \mathrm{OCH}_{2}\left(\mathrm{CH}_{2}\right)_{6} \mathrm{CH}_{3}\right), 3.90(\mathrm{t}, J=7.1 \mathrm{~Hz}, 2 \mathrm{H}$, $\left.\mathrm{OCH}_{2}\left(\mathrm{CH}_{2}\right)_{6} \mathrm{CH}_{3}\right), 3.79\left(\mathrm{t}, J=7.1 \mathrm{~Hz}, 2 \mathrm{H}, \mathrm{OCH}_{2}\left(\mathrm{CH}_{2}\right)_{6} \mathrm{CH}_{3}\right), 3.35(\mathrm{~d}, J=14.2 \mathrm{~Hz}, 2 \mathrm{H}$, $\mathrm{ArCH} \mathrm{Ar}_{2} \mathrm{Ar}, 3.30$ (d, $\left.J=14.2 \mathrm{~Hz}, 2 \mathrm{H}, \mathrm{ArCH}_{2} \mathrm{Ar}\right), 1.85\left(\mathrm{~m}, 8 \mathrm{H}, \mathrm{OCH}_{2} \mathrm{CH}_{2}\left(\mathrm{CH}_{2}\right)_{5} \mathrm{CH}_{3}\right), 1.29$ $\left(\mathrm{m}, 40 \mathrm{H}, \mathrm{O}\left(\mathrm{CH}_{2}\right)_{2}\left(\mathrm{CH}_{2}\right)_{5} \mathrm{CH}_{3}\right), 0.89\left(\mathrm{t}, \mathrm{J}=6.3 \mathrm{~Hz}, 12 \mathrm{H}, \mathrm{O}\left(\mathrm{CH}_{2}\right)_{7} \mathrm{CH}_{3}\right) .{ }^{13} \mathrm{C} \mathrm{NMR}(75 \mathrm{MHz}$, $\left.\mathrm{CDCl}_{3}\right) \delta 162.6,161.2,155.7,142.8,142.4,137.4,135.7,134.9,132.9,128.3,124.6,123.6$, 122.6, 75.9, 75.5, 31.8, 31.0, 30.3, 30.2, 29.7, 29.5, 29.4, 26.3, 26.2, 25.9, 22.6, 14.0. MS (ESI): calculated for $[\mathrm{M}+\mathrm{Na}]^{+} \mathrm{m} / z=1030.7$; found $\mathrm{m} / z=1030.5$. El. Anal. calculated for $\mathrm{C}_{60} \mathrm{H}_{85} \mathrm{~N}_{3} \mathrm{O}_{10}$ : C 71.47, $\mathrm{H}$ 8.50, N 4.17; found: C 71.29, H 8.63, N 4.01.

5,17-Diamino-25,26,27,28-tetraoctyloxycalix[4]arene (8a). This compound was prepared with the same procedure used for compound 3a starting from 7a and obtained as a pale brown powder in $84 \%$ yield. M.p.: $158-160{ }^{\circ} \mathrm{C}\left(\mathrm{CH}_{2} \mathrm{Cl}_{2}\right) \cdot{ }^{1} \mathrm{H}$ NMR $\left(300 \mathrm{MHz}, \mathrm{CDCl}_{3}\right) \delta$ $6.74(\mathrm{~d}, J=7.4 \mathrm{~Hz}, 4 \mathrm{H}, \operatorname{Ar} H), 6.64(\mathrm{t}, J=6.6 \mathrm{~Hz}, 2 \mathrm{H}, \operatorname{Ar} H), 5.95(\mathrm{~s}, 4 \mathrm{H}, \operatorname{Ar} H), 4.40(\mathrm{~d}, J=$ $13.3 \mathrm{~Hz}, 4 \mathrm{H}, \mathrm{ArCH} \mathrm{Ar}_{2}, 3.89$ (t, $\left.J=7.5 \mathrm{~Hz}, 4 \mathrm{H}, \mathrm{OCH}_{2}\left(\mathrm{CH}_{2}\right)_{6} \mathrm{CH}_{3}\right), 3.78(\mathrm{t}, J=7.3 \mathrm{~Hz}, 4 \mathrm{H}$, $\mathrm{OCH}_{2}\left(\mathrm{CH}_{2}\right)_{6} \mathrm{CH}_{3}$ ), 3.19 (d, $J=13.3 \mathrm{~Hz}, 4 \mathrm{H}, \mathrm{ArCH} \mathrm{H}_{2} \mathrm{Ar}$ ), 2.99 (brs, 4H, ArNH $\left.H_{2}\right), 1.87$ (m, $\left.8 \mathrm{H}, \mathrm{OCH}_{2} \mathrm{CH}_{2}\left(\mathrm{CH}_{2}\right)_{5} \mathrm{CH}_{3}\right), 1.34\left(\mathrm{~m}, 40 \mathrm{H}, \mathrm{O}\left(\mathrm{CH}_{2}\right)_{2}\left(\mathrm{CH}_{2}\right)_{5} \mathrm{CH}_{3}\right), 0.91(\mathrm{t}, J=6.2 \mathrm{~Hz}, 12 \mathrm{H}$, $\left.\mathrm{O}\left(\mathrm{CH}_{2}\right)_{7} \mathrm{CH}_{3}\right) .{ }^{13} \mathrm{C}$ NMR $\left(75 \mathrm{MHz}, \mathrm{CDCl}_{3}\right) \delta 156.9,149.8,140.3,135.4,128.1,121.7$, 115.7, 75.1, 75.0, 32.0, 31.0, 30.3, 29.9, 29.6, 26.4, 26.3, 22.7, 14.1. MS (ESI): calculated for $[\mathrm{M}+\mathrm{Na}]^{+} \mathrm{m} / z=925.7$; found $m / z=925.8$. El. Anal. calculated for $\mathrm{C}_{60} \mathrm{H}_{90} \mathrm{~N}_{2} \mathrm{O}_{4}: \mathrm{C}$ 79.77, H 10.04, N 3.10; found: C 79.55, H 10.27, N 3.19. 
5,11,17-Triamino-25,26,27,28-tetraoctyloxycalix[4]arene (8b). This compound was prepared with the same procedure used for compound 3a starting from $\mathbf{7 b}$ and obtained as a pale brown powder in $91 \%$ yield. M.p.: $168-170{ }^{\circ} \mathrm{C} .{ }^{1} \mathrm{H}$ NMR $\left(300 \mathrm{MHz}, \mathrm{CDCl}_{3}\right) \delta$ $6.74(\mathrm{~d}, J=6.6 \mathrm{~Hz}, 2 \mathrm{H}, \operatorname{Ar} H), 6.66(\mathrm{t}, J=6.6 \mathrm{~Hz}, 1 \mathrm{H}, \operatorname{Ar} H), 6.09(\mathrm{~s}, 2 \mathrm{H}, \operatorname{Ar} H), 6.00(\mathrm{~d}$, $J=2.6 \mathrm{~Hz}, 2 \mathrm{H}, \operatorname{Ar} H), 5.95(\mathrm{~d}, J=2.5 \mathrm{~Hz}, 2 \mathrm{H}, \operatorname{Ar} H), 4.39(\mathrm{~d}, J=13.2 \mathrm{~Hz}, 2 \mathrm{H}$, $\left.\mathrm{ArCH}_{2} \mathrm{Ar}\right), 4.31\left(\mathrm{~d}, J=13.2 \mathrm{~Hz}, 2 \mathrm{H}, \operatorname{ArCH} H_{2} \mathrm{Ar}\right), 3.88(\mathrm{t}, J=7.5 \mathrm{~Hz}, 2 \mathrm{H}$, $\left.\mathrm{OCH}_{2}\left(\mathrm{CH}_{2}\right)_{6} \mathrm{CH}_{3}\right), 3.81-3.73\left(\mathrm{~m}, 6 \mathrm{H}, \mathrm{OCH}_{2}\left(\mathrm{CH}_{2}\right)_{6} \mathrm{CH}_{3}\right), 3.25$ (brs, $\left.\left.6 \mathrm{H}, \mathrm{ArNH}\right)_{2}\right), 3.04$ (d, $\left.J=13.2 \mathrm{~Hz}, 2 \mathrm{H}, \operatorname{ArCH} H_{2} \mathrm{Ar}\right), 2.92\left(\mathrm{~d}, J=13.2 \mathrm{~Hz}, 2 \mathrm{H}, \operatorname{ArCH}_{2} \mathrm{Ar}\right), 1.89(\mathrm{~m}, 8 \mathrm{H}$, $\left.\mathrm{OCH}_{2} \mathrm{CH}_{2}\left(\mathrm{CH}_{2}\right)_{5} \mathrm{CH}_{3}\right), 1.33\left(\mathrm{~m}, 40 \mathrm{H}, \mathrm{O}\left(\mathrm{CH}_{2}\right)_{2}\left(\mathrm{CH}_{2}\right)_{5} \mathrm{CH}_{3}\right), 0.90(\mathrm{t}, J=6.2 \mathrm{~Hz}, 12 \mathrm{H}$, $\left.\mathrm{O}\left(\mathrm{CH}_{2}\right)_{7} \mathrm{CH}_{3}\right) .{ }^{13} \mathrm{C} \mathrm{NMR}\left(75 \mathrm{MHz}, \mathrm{CDCl}_{3}\right) \delta 156.9,150.0,140.1,140.0,135.8,135.4$, 128.1, 121.4, 115.8, 115:7, 115.4, 75.1, 75.0, 31.9, 31.1, 30.2, 30.1, 29.9, 29.6, 26.4, 26.3, 22.7, 14.0. MS (ESI): calculated for $[\mathrm{M}+\mathrm{Na}]^{+} \mathrm{m} / z=940.7$; found $m / z=940.7$. El. Anal. calculated for $\mathrm{C}_{60} \mathrm{H}_{91} \mathrm{~N}_{3} \mathrm{O}_{4}$ : C 78.47, $\mathrm{H}$ 9.99, N 4.58; found: C 78.30, H 10.18, N 4.32.

5,11-Bis [( $N, N^{\prime}$-di-Boc)guanidine]-25,26,27,28-tetraoctyloxycalix[4]arene cone (9a). This compound was obtained starting from 8a with the same procedure adopted to obtain $4 \mathbf{a}$. The crude was purified by flash column chromatography on silica gel (eluent: hexane/Et $\left.{ }_{2} \mathrm{O} 5: 1\right)$ to obtain the pure product as a white powder in $66 \%$ yield. M.p.: $97-$ $98{ }^{\circ} \mathrm{C}$ dec. $\left(\mathrm{CH}_{2} \mathrm{Cl}_{2}-\mathrm{MeOH}\right) .{ }^{1} \mathrm{H}$ NMR $\left(300 \mathrm{MHz}, \mathrm{CDCl}_{3}\right) \delta 11.68$ (s, 2H, BocNH), 10.25 (s, 2H, ArNH), 7.31 (s, 4H, ArH), 6.24 (t, $J=6.0 \mathrm{~Hz}, 2 \mathrm{H}, \operatorname{Ar} H), 6.17(\mathrm{~d}, J=6.7$ $\mathrm{Hz}, 4 \mathrm{H}, \operatorname{Ar} H), 4.40\left(\mathrm{~d}, J=13.3 \mathrm{~Hz}, 4 \mathrm{H}, \operatorname{ArCH} \mathrm{H}_{2} \mathrm{Ar}\right), 4.01(\mathrm{t}, \mathrm{J}=8.2 \mathrm{~Hz}, 4 \mathrm{H}$, $\left.\mathrm{OCH}_{2}\left(\mathrm{CH}_{2}\right)_{6} \mathrm{CH}_{3}\right), 3.67\left(\mathrm{t}, J=6.4 \mathrm{~Hz}, 4 \mathrm{H}, \mathrm{OCH}_{2}\left(\mathrm{CH}_{2}\right)_{6} \mathrm{CH}_{3}\right), 3.12(\mathrm{~d}, J=13.3 \mathrm{~Hz}, 4 \mathrm{H}$, $\left.\mathrm{ArCH}_{2} \mathrm{Ar}\right), 1.93\left(\mathrm{~m}, 4 \mathrm{H}, \quad \mathrm{OCH}_{2} \mathrm{CH}_{2}\left(\mathrm{CH}_{2}\right)_{5} \mathrm{CH}_{3}\right), 1.85(\mathrm{t}, J=6.9 \mathrm{~Hz}, 4 \mathrm{H}$, $\left.\mathrm{OCH}_{2} \mathrm{CH}_{2}\left(\mathrm{CH}_{2}\right)_{5} \mathrm{CH}_{3}\right), 1.56\left(\mathrm{~s}, 36 \mathrm{H}, \mathrm{Bu}^{\mathrm{t}}\right), 1.51\left(\mathrm{~s}, 36 \mathrm{H}, \quad \mathrm{Bu}^{\mathrm{t}}\right), 1.31(\mathrm{~m}, 40 \mathrm{H}$, $\left.\mathrm{O}\left(\mathrm{CH}_{2}\right)_{2}\left(\mathrm{CH}_{2}\right)_{5} \mathrm{CH}_{3}\right), 0.89\left(\mathrm{~m}, 12 \mathrm{H}, \mathrm{O}\left(\mathrm{CH}_{2}\right)_{7} \mathrm{CH}_{3}\right) .{ }^{13} \mathrm{C}$ NMR $\left(75 \mathrm{MHz}, \mathrm{CDCl}_{3}\right) \delta 155.1$, 153.3, 137.2, 132.8, 130.3, 127.4, 122.6, 122.0, 83.4, 79.3, 75.3, 75.0, 31.9, 31.0, 30.5, 30.0, 29.9, 29.7, 29.4, 28.2, 28.1, 26.6, 26.0, 22.7, 22.6, 14.0. MS (ESI): calculated for $[\mathrm{M}+\mathrm{Na}]^{+} m / z=1409.9$; found $m / z=1409.8$. El. Anal. calculated for $\mathrm{C}_{82} \mathrm{H}_{126} \mathrm{~N}_{6} \mathrm{O}_{12}: \mathrm{C}$ 70.96, H 9.15, N 6.06; found: C 70.68, H 8.93, N 6.27.

5,11,17-Tris[( $N, N^{\prime}$-di-Boc)guanidine]-25,26,27,28-tetraoctyloxycalix[4]arene cone (9b). This compound was obtained starting from $\mathbf{8 b}$ with the same procedure adopted to obtain 4a. The crude was purified by flash column chromatography on silica gel (eluent: hexane/ $\left.\mathrm{Et}_{2} \mathrm{O} 5: 1\right)$ to obtain the pure product as a white powder in $50 \%$ yield. M.p.: 158$160{ }^{\circ} \mathrm{C}$ dec. $\left(\mathrm{CH}_{2} \mathrm{Cl}_{2}-\mathrm{MeOH}\right) .{ }^{1} \mathrm{H}$ NMR $\left(300 \mathrm{MHz}, \mathrm{CDCl}_{3}\right) \delta 11.88$ (s, 2H, BocNH), $11.71(\mathrm{~s}, 1 \mathrm{H}, \operatorname{BocNH}), 10.63$ (s, 2H, ArNH), 9.27 (s, 1H, ArNH), 7.32 (s, 4H, ArH), $6.35(\mathrm{t}, J=7.6 \mathrm{~Hz}, 1 \mathrm{H}, \operatorname{Ar} H), 6.15(\mathrm{~d}, J=7.6 \mathrm{~Hz}, 2 \mathrm{H}, \operatorname{Ar} H), 6.08(\mathrm{~s}, 2 \mathrm{H}, \operatorname{Ar} H), 4.40(\mathrm{~d}$, $\left.J=13.2 \mathrm{~Hz}, 2 \mathrm{H}, \mathrm{ArCH}_{2} \mathrm{Ar}\right), 4.35$ (d, $\left.J=13.2 \mathrm{~Hz}, 2 \mathrm{H}, \mathrm{ArCH}_{2} \mathrm{Ar}\right), 3.97$ (t, $J=7.5 \mathrm{~Hz}$, $\left.4 \mathrm{H}, \mathrm{OCH}_{2}\left(\mathrm{CH}_{2}\right)_{6} \mathrm{CH}_{3}\right), 3.64\left(\mathrm{~m}, 4 \mathrm{H}, \mathrm{OCH}_{2}\left(\mathrm{CH}_{2}\right)_{6} \mathrm{CH}_{3}\right), 3.11(\mathrm{~d}, J=13.2 \mathrm{~Hz}, 4 \mathrm{H}$, ArCH $\left.H_{2} \mathrm{Ar}\right), 1.75-1.92\left(\mathrm{~m}, 8 \mathrm{H}, \mathrm{OCH}_{2} \mathrm{CH}_{2}\left(\mathrm{CH}_{2}\right)_{5} \mathrm{CH}_{3}\right), 1.44-1.54\left(4 \times \mathrm{s}, 54 \mathrm{H}, \mathrm{Bu}^{\mathrm{t}}\right), 1.29$ $\left(\mathrm{m}, 40 \mathrm{H}, \mathrm{O}\left(\mathrm{CH}_{2}\right)_{2}\left(\mathrm{CH}_{2}\right)_{5} \mathrm{CH}_{3}\right), 0.89\left(\mathrm{~m}, 12 \mathrm{H}, \mathrm{O}\left(\mathrm{CH}_{2}\right)_{7} \mathrm{CH}_{3}\right) .{ }^{13} \mathrm{C} \mathrm{NMR}\left(75 \mathrm{MHz}, \mathrm{CDCl}_{3}\right)$ $\delta$ 163.6, 155.4, 155.1, 153.7, 153.4, 153.3, 153.2, 152.9, 137.1, 137.0, 133.4, 133.0, $130.3,129.9,127.4,123.1,122.5,121.6,83.4,82.9,79.3,78.8,75.1,75.0,31.9,31.1$, $30.5,30.4,30.0,29.9,29.7,29.4,28.1,28.0,26.6,25.9,22.7,22.6,14.0$. MS (ESI): calculated for $[\mathrm{M}+\mathrm{Na}]^{+} \mathrm{m} / \mathrm{z}=1667.1$; found $\mathrm{m} / \mathrm{z}=1666.8$. El. Anal. calculated for $\mathrm{C}_{93} \mathrm{H}_{145} \mathrm{~N}_{9} \mathrm{O}_{16}$ : C 67.89, H 8.88, N 7.66; found: C 68.14, H 8.66, N 7.40. 
5,11-Bisguanidinium-25,26,27,28-tetraoctyloxycalix[4]arene, dichloride salt cone (2G4Octcone). The compound pure was obtained by crystallization from acetone as a white powder in $71 \%$ yield. M.p.: $277-279{ }^{\circ} \mathrm{C}$ dec. (acetone). ${ }^{1} \mathrm{H}$ NMR (300 MHz, $\left.\mathrm{CD}_{3} \mathrm{OD}\right) \delta 7.07$ (d, $J=7.5 \mathrm{~Hz}, 4 \mathrm{H}$, $\operatorname{Ar} H), 6.86(\mathrm{t}, J=7.5 \mathrm{~Hz}, 2 \mathrm{H}, \mathrm{Ar} H), 6.02(\mathrm{~s}, 4 \mathrm{H}, \operatorname{Ar} H), 4.46\left(\mathrm{~d}, J=13.2 \mathrm{~Hz}, 4 \mathrm{H}, \operatorname{ArCH} H_{2} \mathrm{Ar}\right), 4.09$ $\left(\mathrm{t}, J=8.1 \mathrm{~Hz}, 4 \mathrm{H}, \mathrm{OCH}_{2}\left(\mathrm{CH}_{2}\right)_{6} \mathrm{CH}_{3}\right), 3.74\left(\mathrm{t}, J=6.3 \mathrm{~Hz}, 4 \mathrm{H}, \mathrm{OCH}_{2}\left(\mathrm{CH}_{2}\right)_{6} \mathrm{CH}_{3}\right), 3.17(\mathrm{~d}, J=13.2$ $\left.\mathrm{Hz}, \quad 4 \mathrm{H}, \quad \mathrm{ArCH} \mathrm{H}_{2} \mathrm{Ar}\right), \quad 1.64-1.92\left(\mathrm{~m}, \quad 8 \mathrm{H}, \quad \mathrm{OCH}_{2} \mathrm{CH}_{2}\left(\mathrm{CH}_{2}\right)_{5} \mathrm{CH}_{3}\right), \quad 1.22-1.51 \quad(\mathrm{~m}, \quad 40 \mathrm{H}$, $\left.\mathrm{O}\left(\mathrm{CH}_{2}\right)_{2}\left(\mathrm{CH}_{2}\right)_{5} \mathrm{CH}_{3}\right), 0.91\left(\mathrm{~m}, 12 \mathrm{H}, \mathrm{O}\left(\mathrm{CH}_{2}\right)_{7} \mathrm{CH}_{3}\right) .{ }^{13} \mathrm{C} \mathrm{NMR}\left(75 \mathrm{MHz}, \mathrm{CD}_{3} \mathrm{OD}\right) \delta$ 158.5, 158.0, 156.9, 137.7, 137.1, 130.4, 129.6, 126.0, 124.1, 77.2, 76.7, 33.6, 32.2, 32.1, 31.8, 31.7, 31.5, 31.4, 31.1, 28.3, 27.9, 24.2, 14.8. MS (ESI): calculated for $[\mathrm{M}+\mathrm{H}-2 \mathrm{HCl}]^{+} \mathrm{m} / \mathrm{z}=987.7$; found $\mathrm{m} / \mathrm{z}=$ 987.7.

5,11,17-Trisguanidinium-25,26,27,28-tetraoctyloxycalix[4]arene, trichloride salt cone (3G4Oct-cone). The compound pure was obtained by crystallization from methanol/ethyl acetate as a white powder in $86 \%$ yield. M.p.: $>250{ }^{\circ} \mathrm{C} \mathrm{dec}$. (MeOH-AcOEt). ${ }^{1} \mathrm{H}$ NMR (300 MHz, DMSO$\left.\mathrm{d}_{6}\right) \delta 9.54(\mathrm{~s}, 2 \mathrm{H}, \operatorname{ArNH}), 9.50(\mathrm{~s}, 1 \mathrm{H}, \operatorname{ArNH}), 7.19\left(\mathrm{brs}, 12 \mathrm{H}, H_{2} \mathrm{NCNH} H_{2}\right), 6.75(\mathrm{~s}, 3 \mathrm{H}, \mathrm{Ar} H), 6.64$ (s, 2H, ArH), $6.43(\mathrm{~s}, 2 \mathrm{H}, \mathrm{ArH}), 6.41(\mathrm{~s}, 2 \mathrm{H}, \mathrm{ArH}), 4.32\left(\mathrm{~d}, J=13.0 \mathrm{~Hz}, 2 \mathrm{H}, \mathrm{ArCH}_{2} \mathrm{Ar}\right), 4.29$ (d, $J$ $\left.=13.1 \mathrm{~Hz}, 2 \mathrm{H}, \mathrm{ArCH}_{2} \mathrm{Ar}\right), 3.80-3.96\left(\mathrm{~m}, 8 \mathrm{H}, \mathrm{OCH}_{2}\left(\mathrm{CH}_{2}\right)_{6} \mathrm{CH}_{3}\right), 3.21\left(\mathrm{~m}, 4 \mathrm{H}, \mathrm{ArCH}{ }_{2} \mathrm{Ar}\right), 1.87$ (brs, $\left.8 \mathrm{H}, \quad \mathrm{OCH}_{2} \mathrm{CH}_{2}\left(\mathrm{CH}_{2}\right)_{5} \mathrm{CH}_{3}\right), 1.28-1.48\left(\mathrm{~m}, 40 \mathrm{H}, \mathrm{O}\left(\mathrm{CH}_{2}\right)_{2}\left(\mathrm{CH}_{2}\right)_{5} \mathrm{CH}_{3}\right), 0.86(\mathrm{~m}, 12 \mathrm{H}$, $\left.\mathrm{O}\left(\mathrm{CH}_{2}\right)_{7} \mathrm{CH}_{3}\right) .{ }^{13} \mathrm{C}$ NMR $\left(75 \mathrm{MHz}, \mathrm{CD}_{3} \mathrm{OD}\right) \delta 157.3,157.0,156.4,137.7,136.34,135.7,129.3$, 129.1, 126.5, 125.8, 125.5, 123.3, 76.4, 76.3, 76.1, 32.8, 31.3, 31.2, 31.1, 30.8, 30.7, 30.5, 30.4, 27.4, 27.3, 27.2, 23.4, 14.0. MS (ESI): calculated for $[\mathrm{M}+\mathrm{H}-3 \mathrm{HCl}]^{+} \mathrm{m} / \mathrm{z}=1044.8$; found $\mathrm{m} / \mathrm{z}=$ 1044.8 . 
Figure S2

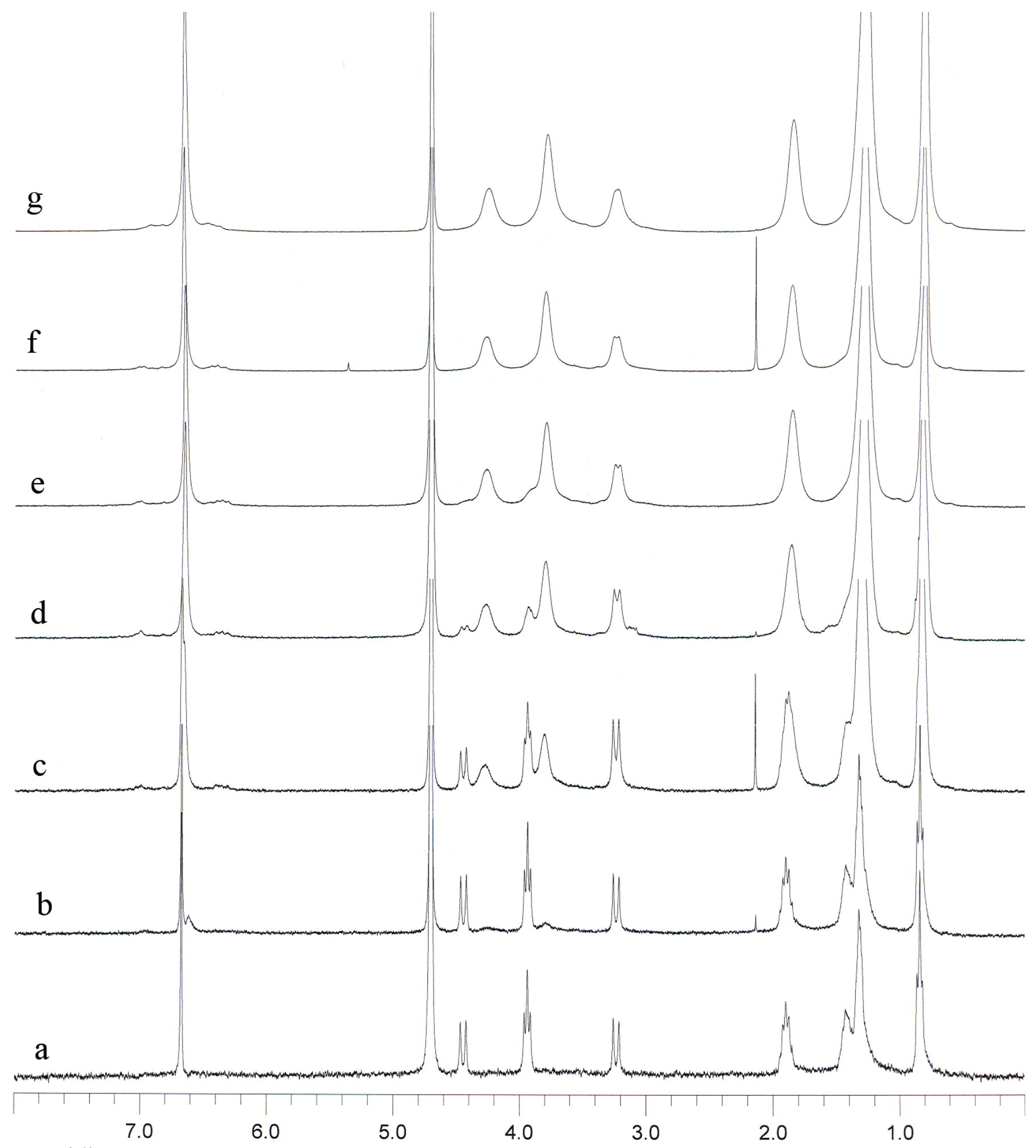

$\operatorname{pom}(\mathrm{t} 1)$

${ }^{1} \mathrm{H}$ NMR spectra (300 MHz, $300 \mathrm{~K}$ ) of $4 \mathrm{G} 4 \mathrm{Hex}-$ cone in $\mathrm{D}_{2} \mathrm{O}$ : a) $0.2 \mathrm{mM}$; b) $0.5 \mathrm{mM}$; c) 1 $\mathrm{mM}$; d) $1.6 \mathrm{mM}$; e) $2.5 \mathrm{mM}$; f) $5 \mathrm{mM}$; g) $10 \mathrm{mM}$. 
Figure S3

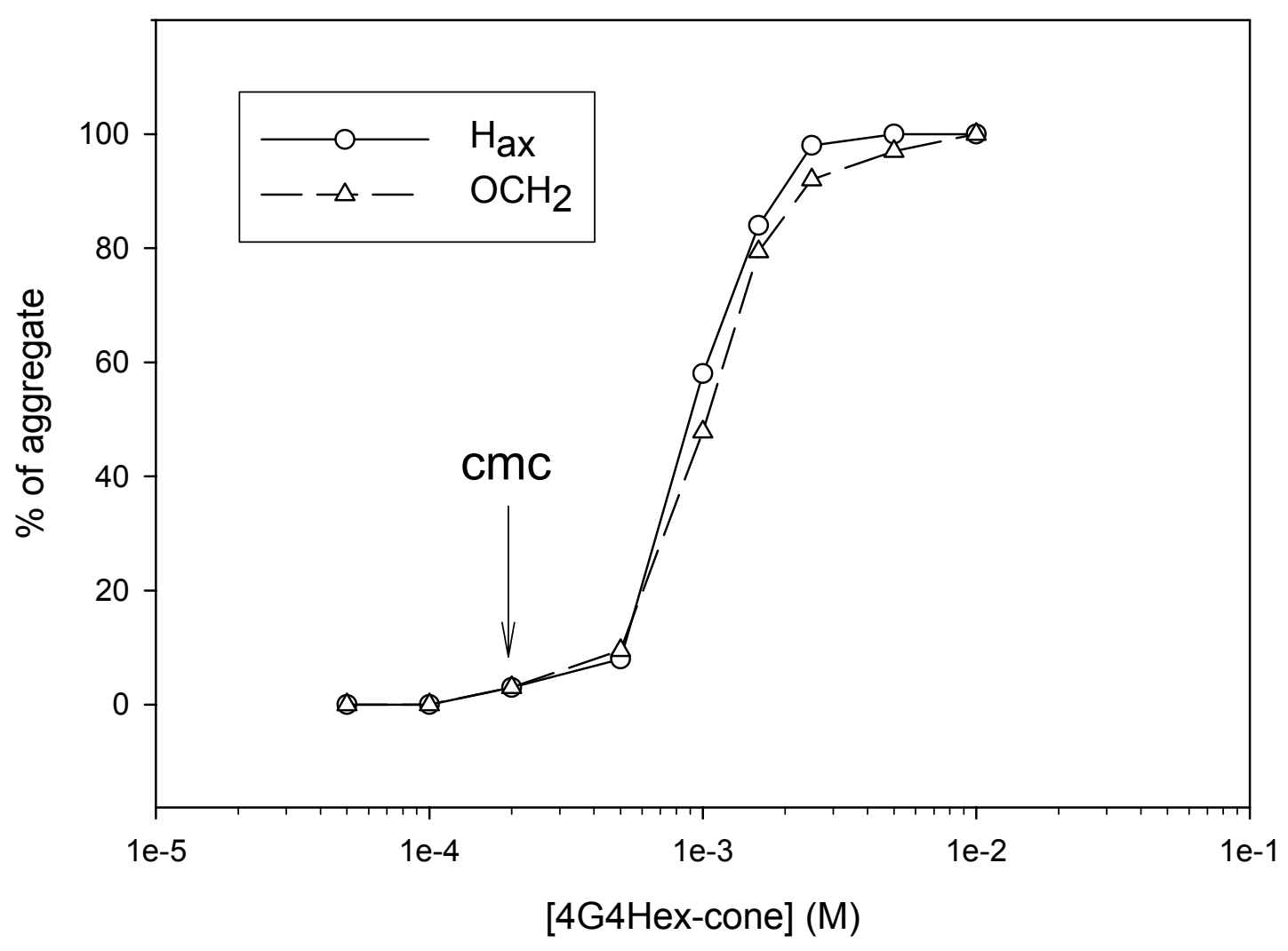


Figure S4
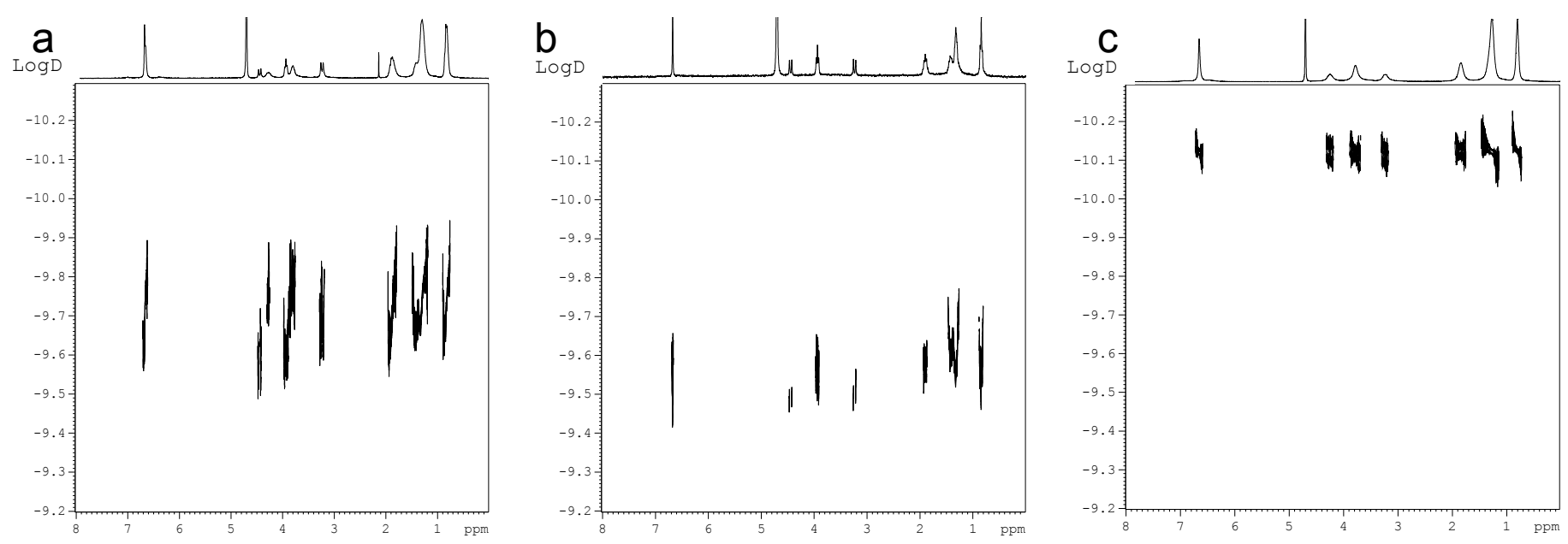

${ }^{1} \mathrm{H}$ DOSY spectra (300 MHz, $298 \mathrm{~K}$ ) of 4G4-Hex-cone in $\mathrm{D}_{2} \mathrm{O}$ : a) $1 \mathrm{mM}$; b) $0.2 \mathrm{mM}$; c) $10 \mathrm{mM}$. 


\section{Figure S5}

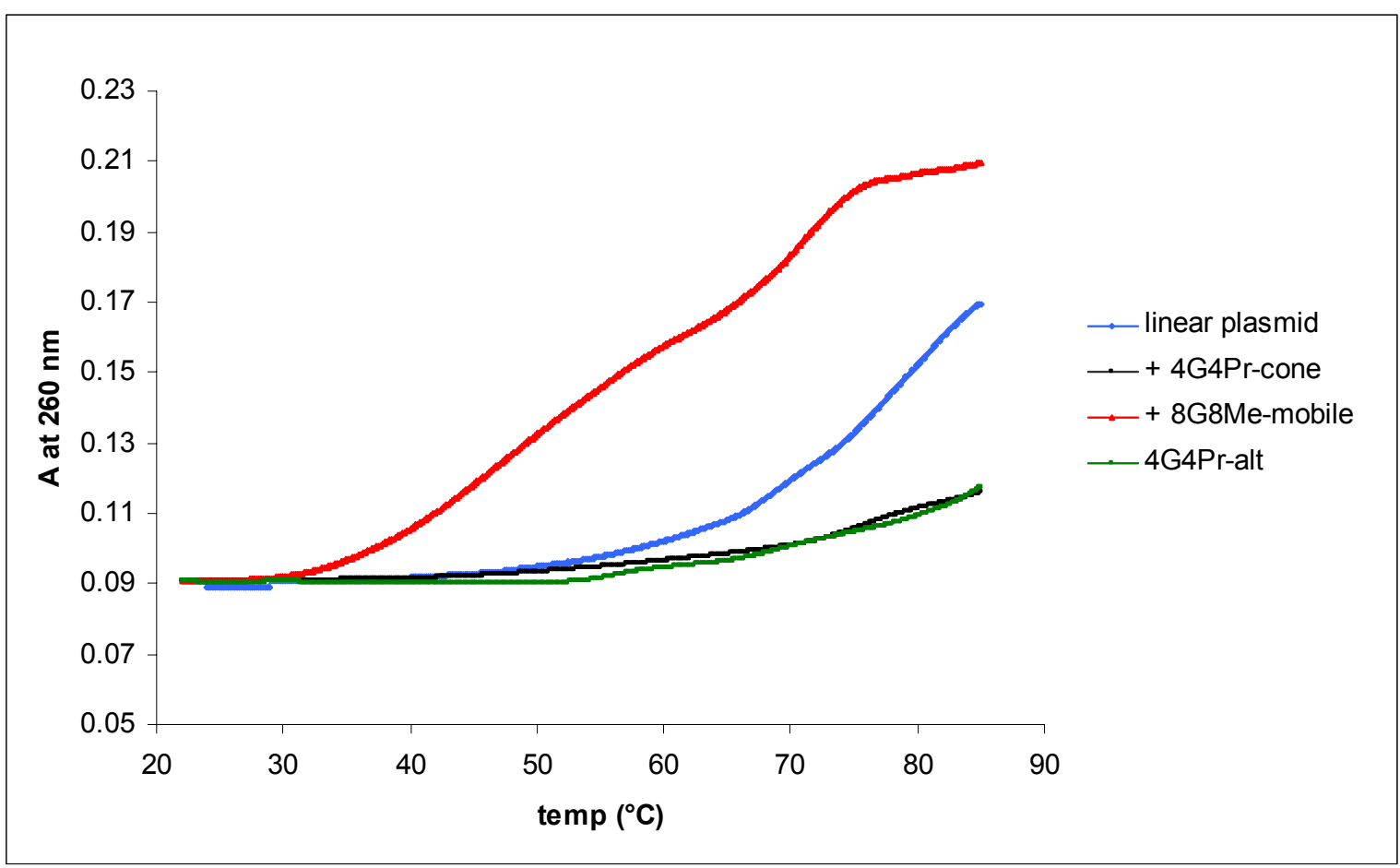

Melting curves for DNA/calixarene complexes. Plasmid DNA (pEGFP-C1) was cut with EcoRI restriction enzyme (Roche), column purified (Genomed) and alcohol precipitated. Linearized plasmid DNA pellet was washed with $70 \%$ of ethanol, air dried and dissolved in distilled $\mathrm{H}_{2} \mathrm{O}$ at a final concentration of 1 $\mu \mathrm{g} / \mathrm{ml}$. Melting curves were obtained monitoring in the range temperature 22-85 ${ }^{\circ} \mathrm{C}$ the absorbance at $260 \mathrm{~nm}$ of buffer solutions (Hepes $4 \mathrm{mM}, \mathrm{NaCl} 10 \mathrm{mM}$ ) of linearized plasmid DNA $4 \mathrm{nM}$ and mixtures of DNA $4 \mathrm{nM}$ and guanidinium calixarene $4 \mu \mathrm{M}$. In the graphic are reported the melting curves obtained for plasmid (blue), plasmid + 4G4Pr-cone (black), plasmid + 4G4Pr-alt (green) and plasmid + 8G8Me-mobile (red). 


\section{Figure S6}

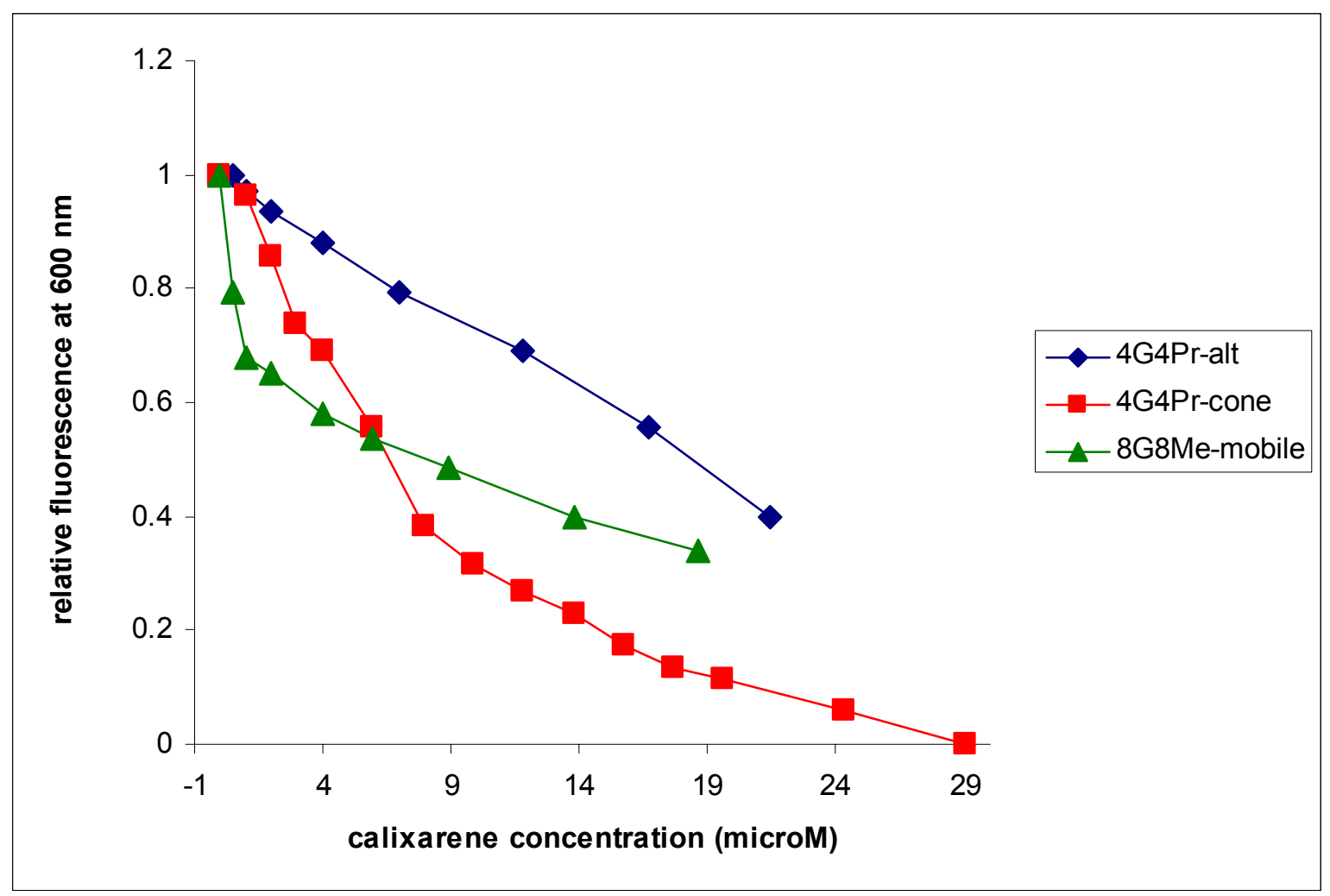

Ethidium bromide displacement assys. Fluorescence studies (excitation at $530 \mathrm{~nm}$, emission at $600 \mathrm{~nm}$ ) were performed collecting the spectra of buffer solutions (Hepes 4 $\mathrm{mM}, \mathrm{NaCl} 10 \mathrm{mM}$ ) of ethidium bromide $50 \mu \mathrm{M}$ (relative fluorescence $=0$ ), a mixture of DNA plasmid (pEGFP-C1) $1 \mathrm{nM}$ and ethidium bromide $50 \mu \mathrm{M}$ (relative fluorescence $=1$ ) and after addition of increasing amounts of guanidinium calixarene. In the graphic are reported the curves obtained for 4G4Pr-cone $(--)$, 4G4Pr-alt (-) and 8G8Memobile $(-\neg)$. 


\section{Figure S7}
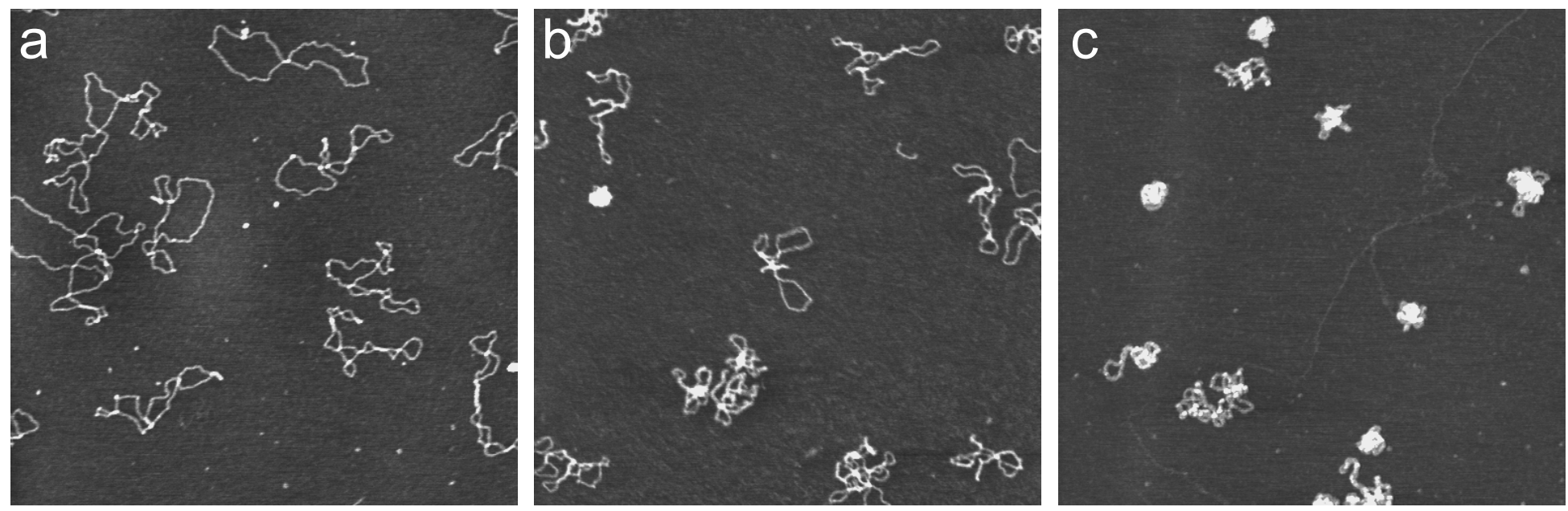

AFM images showing that DNA condensation depends on the concentration of the calixarene. Images were obtained with supercoiled pEGFP-C1 plasmid deposited onto mica at a concentration of $1 \mathrm{nM}$ and incubated with increasing amounts of calixarene 4G4Pr-cone. a) $0.05 \mu \mathrm{M}$; b) $0.5 \mu \mathrm{M}$; c) $5.0 \mu \mathrm{M}$. Each image represents a $2 \times 2 \mu \mathrm{m}$ scan. 


\section{Figure S8}
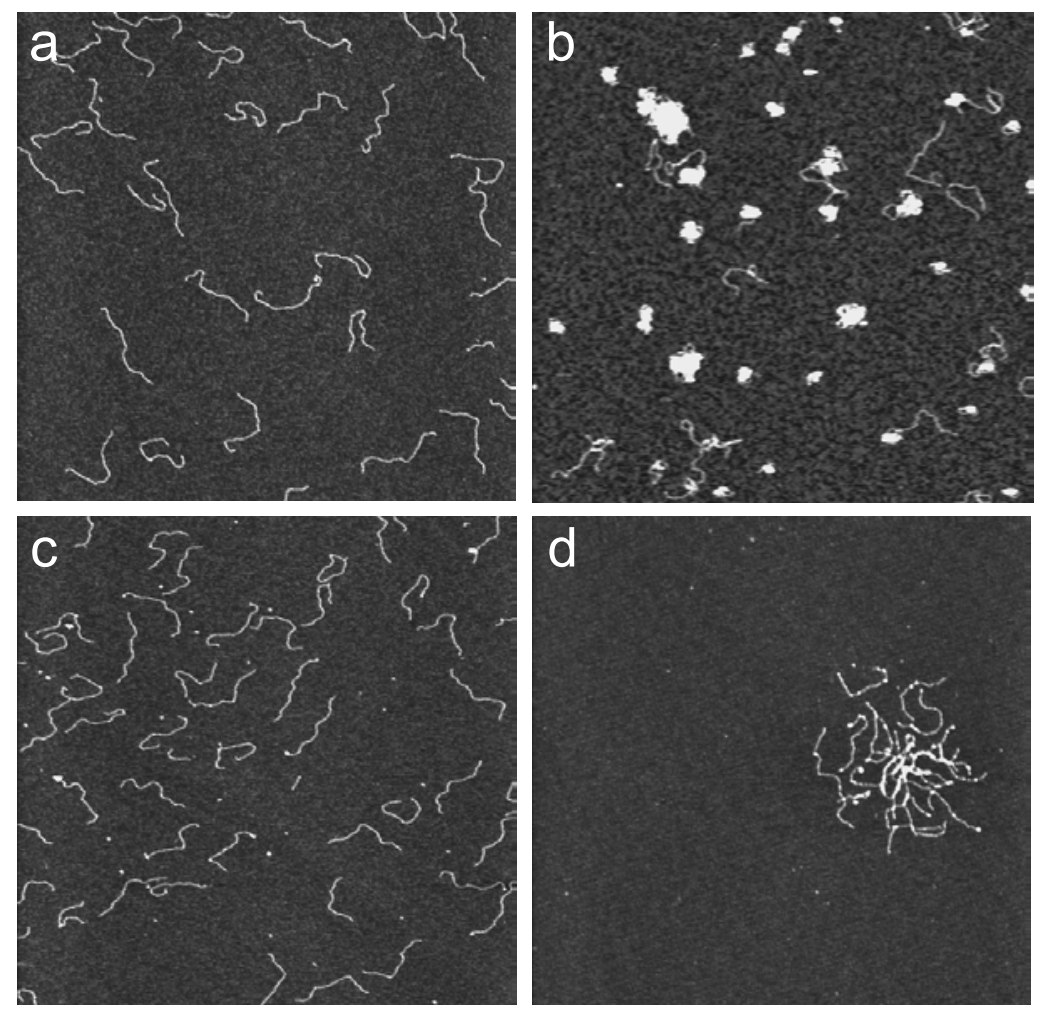

AFM images showing that the condensation properties of calixarenes are independent of DNA topology. Images were obtained with 1200 bp linear DNA fragment deposited onto mica at a concentration of $1 \mathrm{nM}$ and imaged with the tapping mode. a) no calixarene added; b) linear DNA incubated with $1 \mu \mathrm{M}$ calixarene 4G4Pr-cone; c) linear DNA incubated with $1 \mu \mathrm{M}$ calixarene 4G4Pralt; d) linear DNA incubated with $1 \mu \mathrm{M}$ calixarene 6G6Me-mobile. Each image represents a $2 \times 2 \mu \mathrm{m}$ scan. 
${ }^{1} \mathrm{H}$ NMR spectrum $\left(\mathrm{D}_{2} \mathrm{O}, 300 \mathrm{MHz}, 300 \mathrm{~K}\right)$ of guanidinium calix[4]arene 4G4Hex-cone

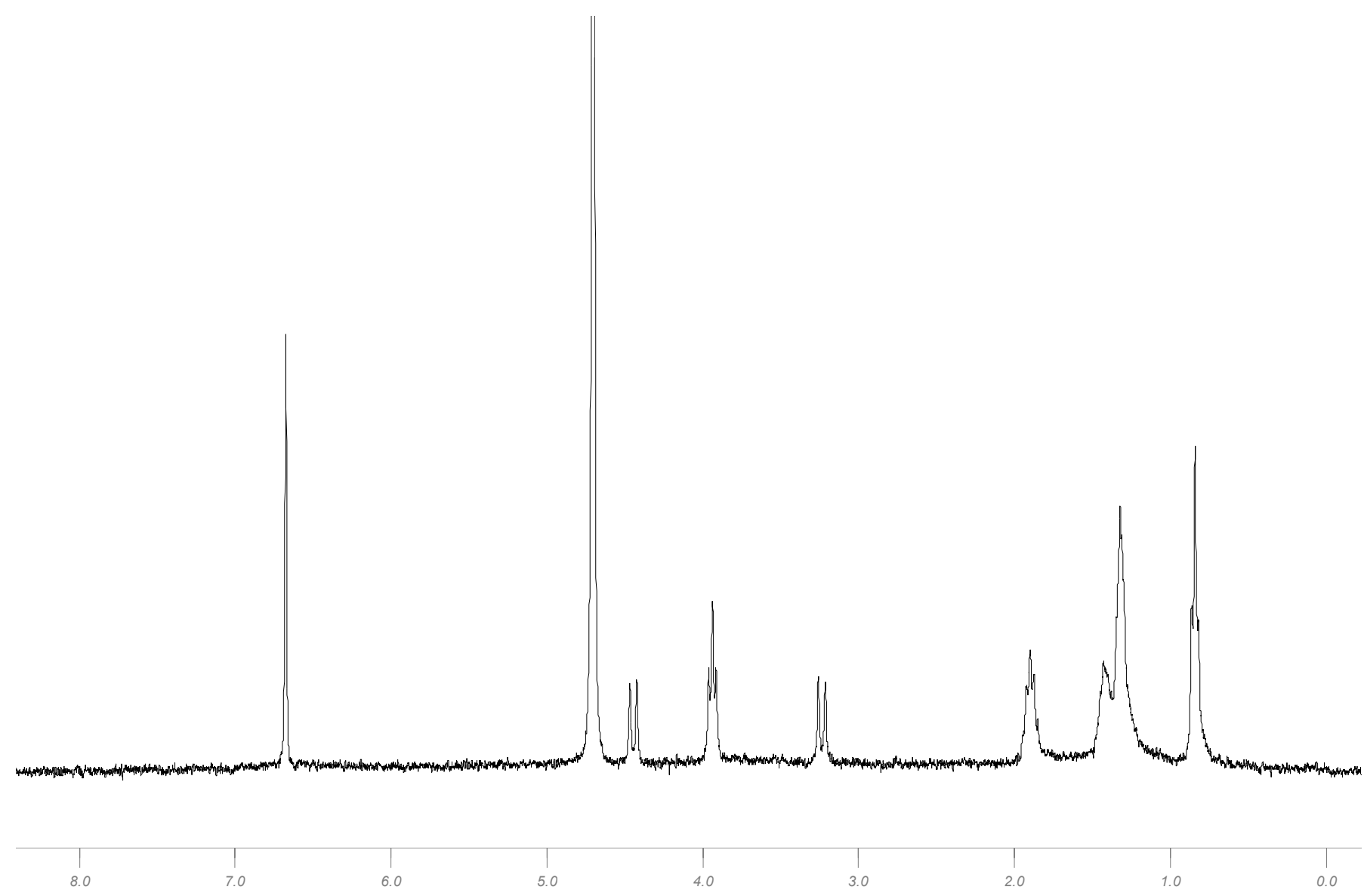

${ }^{1} \mathrm{H}$ NMR spectrum $\left(\mathrm{D}_{2} \mathrm{O}, 300 \mathrm{MHz}, 300 \mathrm{~K}\right)$ of guanidinium calix[4]arene 4G4Pr-alt

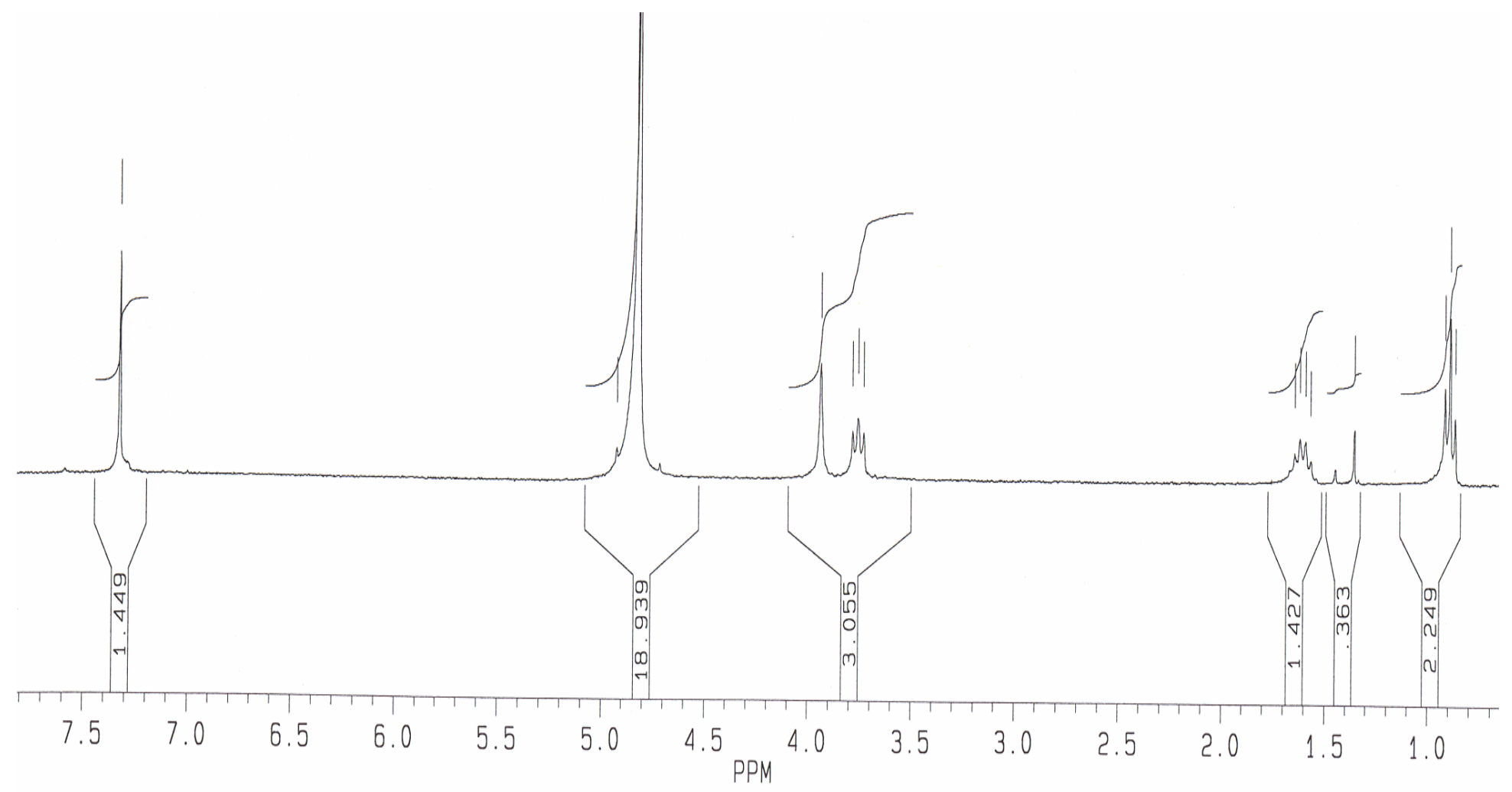


${ }^{1} \mathrm{H}$ NMR spectrum $\left(\mathrm{D}_{2} \mathrm{O}, 300 \mathrm{MHz}, 300 \mathrm{~K}\right)$ of guanidinium calix[4]arene 4G4Me-mobile

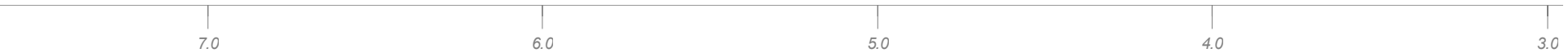

${ }^{1} \mathrm{H}$ NMR spectrum $\left(\mathrm{CD}_{3} \mathrm{OD}, 300 \mathrm{MHz}, 300 \mathrm{~K}\right)$ of guanidinium calix[4]arene 2G4Oct-cone

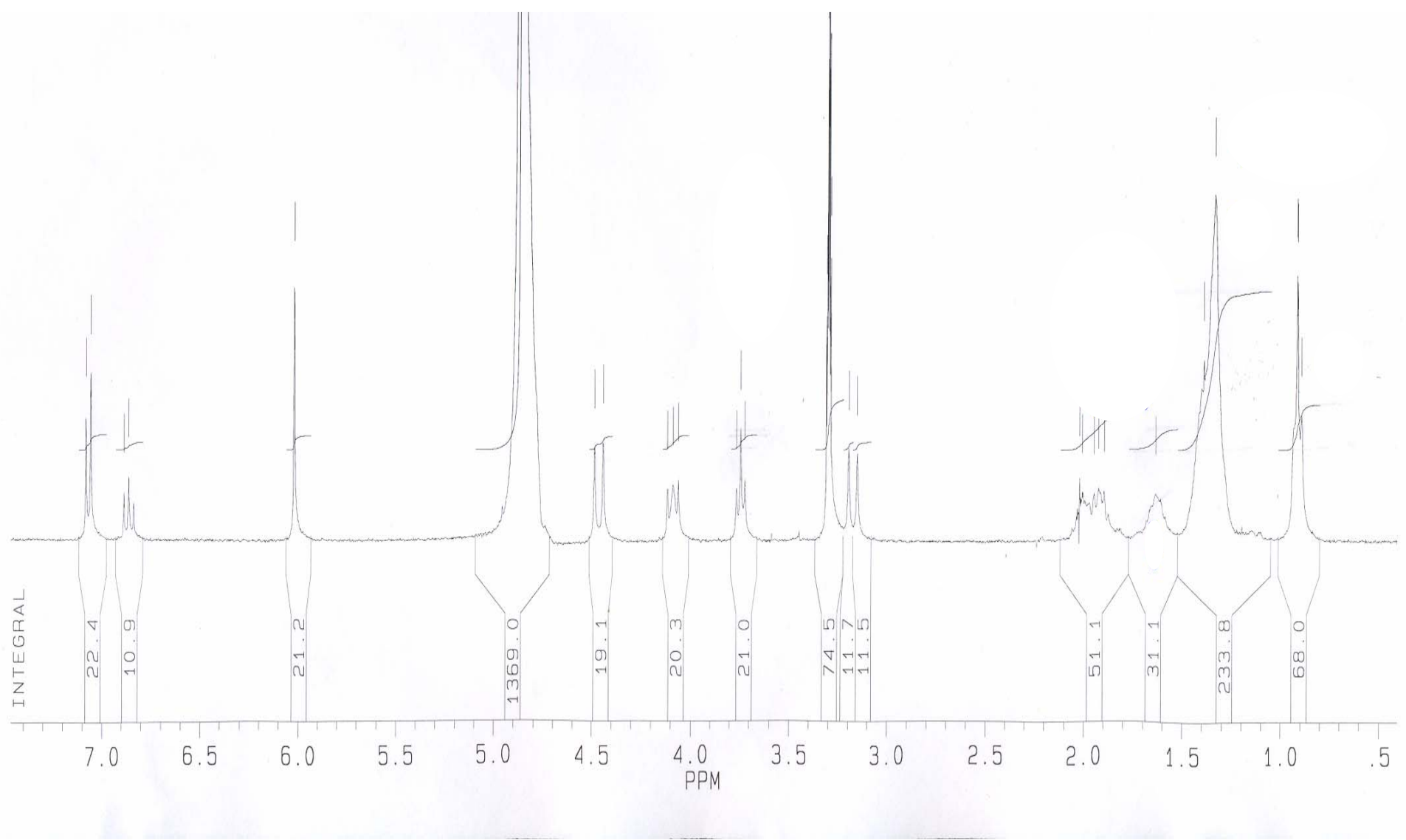


${ }^{1} \mathrm{H}$ NMR spectrum $\left(\mathrm{CD}_{3} \mathrm{OD}, 300 \mathrm{MHz}, 300 \mathrm{~K}\right)$ of guanidinium calix[4]arene 3G4Oct-cone

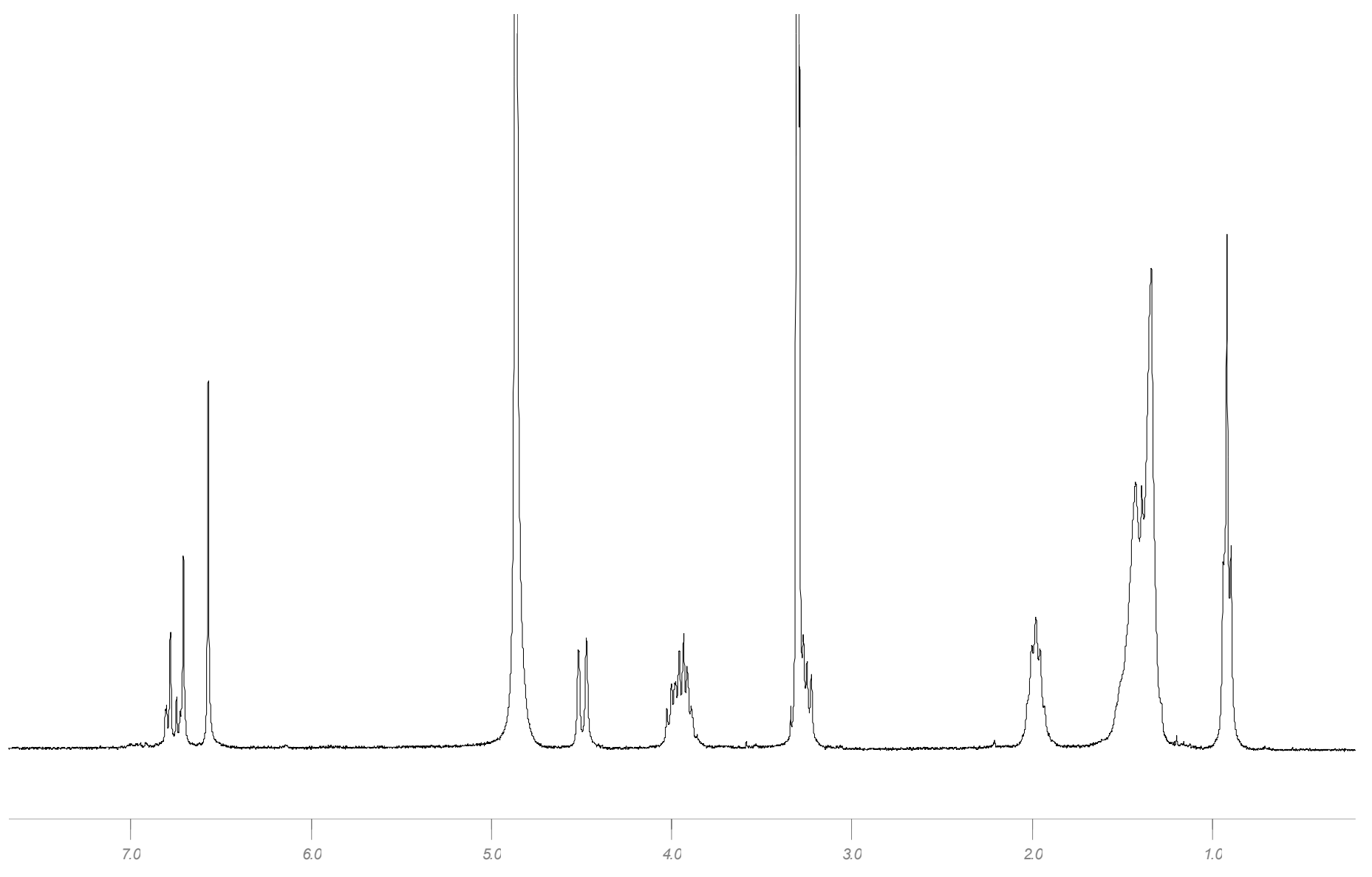

\section{References}

(5) Kirby, A. J.; Camilleri, P.; Engberts, J. B. F. N.; Feiters, M. C.; Nolte, R. J. M.; Söderman, O.; Bergsma, M.; Bell, P. C.; Fielden, M. L.; Rodríguez, C. L. G.; Guédat, P.; Kremer, A.; McGregor, C.; Perrin, C.; Ronsin, G.; van Eijk, M. C. P. Angew. Chem. Int. Ed. 2003, 42, 1448-1457. 